\title{
Medical school admission requirements lock out many Indigenous students
}

\author{
— Cite as: CMAJ 2018 July 3;190:E809. doi: 10.1503/cmaj.109-5622
}

Posted on cmajnews.com on June 12, 2018.

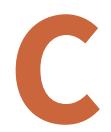
anada needs more Indigenous health providers, but education systems are standing in their way, according to speakers at the Indigenous Health Conference, held recently in Toronto. They urged medical schools to relax admissions requirements and increase outreach and supports for Indigenous students, starting in high school.

More Indigenous health workers could help close gaps in care because they are more likely to serve their own communities and provide culturally appropriate care. But the academic and financial demands of health care training pose major barriers, said Dr. Kent Saylor, director of the Indigenous Health Professions Program at McGill University.

Most successful medical school applicants come from wealthy, urban families and have high grades in addition to a resumé full of other achievements, he explained. Indigenous youth, by contrast, often receive lower-quality education and lack the extracurricular opportunities that would distinguish them in admissions processes. Just $42 \%$ of those living on reserve attain a high school degree or higher education, compared to $90 \%$ of the general population.

Given this reality, the emphasis on academics in admissions is "problematic," said Saylor. McGill doesn't have an official grade cutoff, but if a student's average is below an A, "you're not going to get looked at." Some schools with protected spots for Indigenous students will admit those with "slightly lower" grades, and those students are thriving, he said. However, Saylor argued that schools should go a step further and drop the grade requirement entirely. "There's no evidence that a high grade-point average

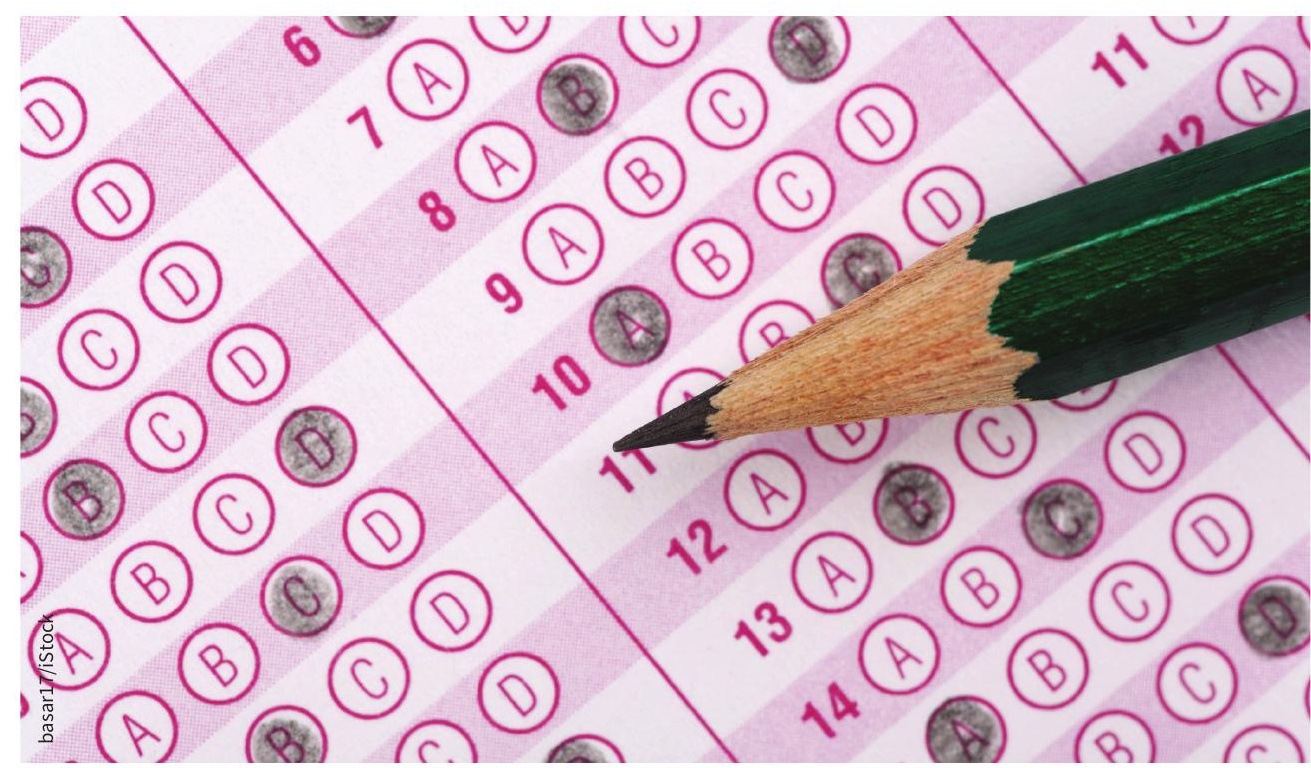

Emphasizing academics in medical school admissions puts Indigenous students at a disadvantage, according to medical educator Dr. Kent Saylor.

means you're going to be a better doctor. I might even argue it's maybe worse."

Schools also need to make it known that Indigenous students are welcome in medicine by doing active outreach and creating pipeline programs to close the education gap, he said. Saylor recalled the warm reception he received at Stanford University as a medical school applicant after he failed to secure an interview at Canadian schools. "I was greeted by an Indigenous faculty member who asked me, 'What can we do to get you to come here?" He noted it was the first time in his life that his Indigenous heritage was treated as "something special."

Some schools host health-career camps to give students a taste of working in health care. The Northern Ontario School of Medicine's camp in Iqaluit combines hands-on activities like setting a cast with talks by elders about traditional practices. It's important to blend the two, "to preserve culture and get our kids educated, rather than it being separated," said Saylor.

Respect for cultural differences must continue into training, said Amanda Rogers, a graduate student of nursing at the University of New Brunswick. Accommodation of cultural differences has proven to be a key factor in the success of Indigenous nursing students. Other supportive factors included relationships with Indigenous peers and faculty, and programs enforcing a policy of zero tolerance for racism. "Not only are students grappling with their colonial history and navigating through a program that doesn't reflect their way of being, but to have that intersect with racism is extremely challenging," Rogers said.

Lauren Vogel, CMAJ 